\title{
Review of Different Methods of Uncinectomy in Endoscopic Sinus Surgery
}

\author{
Haitham Alnori \\ Department of Surgery, College of Medicine, University of Mosul , Mosul , Iraq \\ Correspondence: haithamabdnori@uomosul.edu.iq
}

(Ann Coll Med Mosul 2021; 43 (1):70-75).

Received: $19^{\text {th }}$ Febr. 2021; Accepted: $15^{\text {th }}$ March 2021.

\section{ABSTRACT}

Uncinectomy is a safe procedure in experienced hands whatever technique is used. It is usually the first step in endoscopic sinus surgery and the first surgical maneuver the new rhinologist has to learn. The most familiar two methods of doing uncinectomy are the classic method, introduced by Stammberger in 1986, and Wormald's swing-door technique in 1998. The swing-door technique appears to be associated with a slightly higher risk of injury to the lacrimal duct. Simultaneously, failure to identify maxillary ostium and orbital penetration are both more common in the classic method.

This study aims to review the different methods of doing uncinectomy during endoscopic sinus surgery and compare the most standard techniques regarding their efficiency and safety.

Keywords: uncinectomy, endoscopic sinus surgery, swing-door technique , classic uncinectomy .

$$
\begin{aligned}
& \text { مراجعة الطرق المختلفة لقص الخطاف في جراحة الجيوب الأنفية } \\
& \text { بالمنظار } \\
& \text { هيثم عبد الملك النوري } \\
& \text { فرع الجراحة ، كلية الطب ، جامعة الموصلّ ، الموصل ، الورئ ، العراق }
\end{aligned}
$$

يعتبر قص الخطاف إجر اءٌ آمنًا فى أيدى ذوى الخبرة مها كانت التقنية المستخدمة. عادة ما تكون الخطوة الأولى فى جراحة

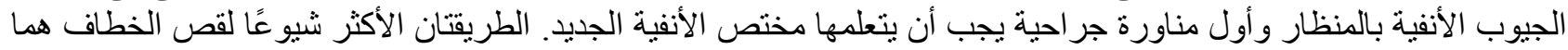

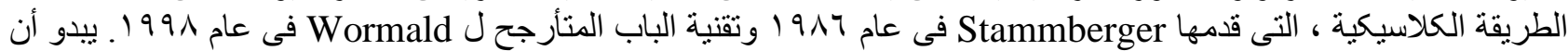

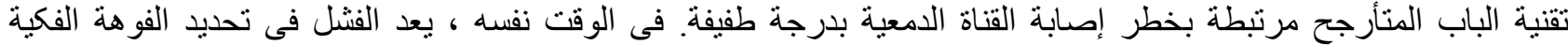

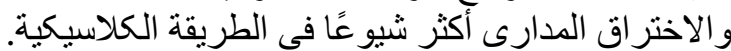

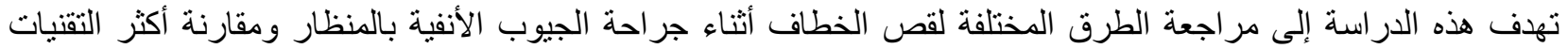
القياسية فيما يتعلق بكفاءتها وسلامتها. الكلمات المفتاحية : قص الخطاف ، عمليات الجيوب الانفية المنظارية ، تقنية الباب المتأرجح ، قص الخطاف التقليدي .

\section{INTRODUCTION}

$\mathrm{T}$ he uncinate process is a curvilineal mucosal eminence that lies at the anterior end of the middle meatus. It is composed of thin bone that is covered by mucosa on both sides ${ }^{1,2}$. Stammberger has established the concept of functional endoscopic sinus surgery (FESS) in 1986. It is based on opening the drainage pathway of the sinuses while keeping the large sinuses untouched. The area of concern here is the ostiomeatal complex, a functional unit comprising the middle meatus drainage pathway, which consists of the uncinate process, ethmoid infundibulum and the anterior ethmoid complex ${ }^{2}$. The uncinate is usually involved in inflammatory conditions of the sinuses very early in the disease process, and uncinectomy is usually the first step in FESS. Moreover, the maxillary sinus ostium is situated just behind it in most patients, and one can enter the maxillary and frontal sinus under good visualization after proper uncinectomy. 
While talking about partial uncinectomy in minimal sinus diseases, complete uncinectomy is mandatory whenever there is an extensive disease or firmly established inflammatory process as in patients with allergic fungal sinusitis and coexistent bronchial asthma ${ }^{3-5}$.

\section{Anatomical Considerations}

The uncinate process is a thin, sickle-shaped structure that is part of the ethmoid bone and runs in the sagittal plane from anterosuperiorly to posteroinferiorly. It has a free margin posteriorly that lies parallel to the anterior surface of the bulla ethmoidalis. Between the uncinate process and the ethmoid bulla lies the hiatus semilunaris, a crescent-shaped cleft that forms the entrance to the ethmoidal infundibulum. Inferiorly the uncinate is attached to the ethmoid process of the inferior turbinate and the perpendicular process of the palatine bone. Anteriorly it is attached to the lacrimal bone and sometimes to the middle turbinate. Superiorly it is inserted in different ways. The ethmoidal infundibulum configuration depends mainly on the pattern of insertion of the uncinate process: if it is curved laterally toward lamina papyracea, the ethmoidal infundibulum ends in a blind sac, the terminal recess. If the uncinate process is inserted to the skull base superiorly or curves medially to attach to the middle turbinate, the ethmoidal infundibulum is continuous with the frontal recess superiorly ${ }^{2,6}$. The uncinate process may show some variations; it may be medialized, everted (paradoxical), or aerated (uncinate bulla). These configurations and variations significantly impact the anatomy and physiology of the anterior group of sinuses drainage pathway, namely the frontal, maxillary, and anterior ethmoidal sinuses. CT scan of the ostiomeatal complex must be studied carefully and in different planes before performing FESS. The ethmoidal infundibulum width is evaluated by taking the distance from the uncinate process to the medial orbital wall in a coronal CT $\operatorname{scan}^{2,8}$.

\section{Description of The Techniques}

Up to now, there are many ways of doing uncinectomy; some describe more than 15 different methods. The basic idea is to remove the uncinate flush with the lateral nasal wall while not causing injury to the orbital wall and lacrimal system. After "good uncinectomy", the natural maxillary sinus ostium should be readily identified, usually with a 30-degree endoscope. Moreover, some techniques are primarily designed to identify and remove the uncinate under challenging situations, as in revision surgery where scarring and polypoid tissue prevents adequate visualization.

Generally, the technique of uncinectomy is broadly divided into two main types. In the first type, surgeons adopt anterior to posterior dissection. This type has been described by Stammberger in 1986 and is performed by a sickle knife. He illustrated the method in more than one publication and referred it to the "Messerklinger technique" 4 . In the second type, the uncinate process is removed in a retrograde fashion, i.e. from posterior to anterior. Wormald popularized this procedure in 1998 and called it the swing-door technique $^{9}$

The Classic Uncinectomy: With the aid of a zerodegree endoscope, the uncinate is visualized after gentle medialization of the middle turbinate. The uncinate process is checked by insertion of a blunt ball probe into hiatus semilunaris, making sure of the presence of air-space behind the uncinate, and understanding its shape and attachment. The sickle knife or sharp dissector then performs Uncinectomy. The sickle knife is inserted just in front of and immediately below the uncinate process's upper insertion. Full-thickness of the uncinate process (outer mucosa, bone, and inner mucosa) should be included. The cut is extended in a downward convex shape to the level of the inferior turbinate. If the frontal sinus is to be opened, the sickle knife is turned upward, and the cut is extended toward but not touching the axilla of the middle turbinate. While cutting the uncinate, the side of the sickle knife is used to gently push the uncinate medially so that the tip of the knife is seen in the hiatus semilunaris. By doing so, the procedure is done under direct vision, and there is less risk of violation to the lamina papyracea. The cut uncinate is then removed by a suitable instrument, preferably by straight Blakesley forceps (figure 1). Now 30-degree endoscope is used to visualize the maxillary sinus ostium. The remaining horizontal segment of the uncinate process is part of the common drainage pathway. Every effort is spent on maintaining mucosa of this pathway intact, as excess manipulation and traumatization may cause scarring. The horizontal uncinate is dissected free submucosally by a blunt ball probe, and its bone is removed by one of the straight biting forceps. If mucosa became redundant, it is trimmed by side-biting forceps or the microdebrider 1,4

Some surgeons prefer cutting the upper and lower attachments of the uncinate before its removal; after making an incision by the sickle knife, the remaining superior attachment can be cut with one of the rhinologic scissors as Zurich scissors, and 
the same is done at its inferior attachment. These cuts prevent stripping of mucosa ${ }^{8}$.

The Swing-Door Technique: The technique was initially developed in an attempt to achieve "complete uncinectomy", aiming at better exposure of natural maxillary sinus ostium. A ball probe is used to palpate the uncinate and confirms the position of its free posterior margin. The midsection of the uncinate is cut superiorly and inferiorly. The pediatric backbiter is introduced in the middle meatus and opened, then allowed to engage the posterior edge of the uncinate at the junction of its middle and horizontal parts. Usually, more than one bite is necessary to cut the uncinate down to its attachment to the bone of the nasolacrimal duct. The upper incision is done with a sickle knife just below the axilla. The sickle knife is passed almost horizontally, cutting the upper part of the uncinate from its posterior free edge up to the frontal process of the maxilla. An angled ball probe or curved curette is slid behind the uncinate and pulled anteriorly to fracture the uncinate close to its insertion at the lateral nasal wall. An up-biting Blakesley forceps is introduced through the lower cut and used to remove the uncinate flush with the lateral nasal wall. The view is now changed to a 30-degree endoscope to visualize the maxillary ostium. The horizontal segment of the uncinate is removed in an almost similar fashion to that described in the classic method ${ }^{3,9}$.

Several authors have proposed different modifications of the original swing-door technique for one reason or another. One modification is to make the upper incision by the back-biter to avoid any possible injury to lamina papyracea caused by the sickle knife. Although no such injury has occurred in the author's hands, it still may happen with the less experienced surgeon if the sickle knife is used $^{8,10}$.

Some authors suggest that only the lower incision is required, and it is done by the small backbiter as originally described. After that, an up biting through-cutting forceps or small Hajek punch can nibble away upward at the uncinate process to take it incrementally ${ }^{8}$.

In the era of powered instruments, surgery became faster with more precision. The lower incision is given by the pediatric backbiter as described. The uncinate process is fractured medially by angled ball probe or curved curette and then removed by the microdebrider (figure 2) $5,8,10$

Some of the pioneer surgeons in the field of rhinology have adopted the swing-door technique. Casiano described a similar technique to the original swing-door and finally removed the uncinate with back-biter or powered instruments ${ }^{5}$.
Castelnuovo et al. described a similar method with emphases on identifying the site of attachment of the uncinate to the lateral nasal wall before its resection. This is facilitated by a blunt ball probe pressing gently on the edge of the uncinate process; the uncinate shows some mobility while the frontal process of the maxilla is totally immobile. Also, they felt that the upper incision of the uncinate is not necessary as the lower one is sufficient to fracture the uncinate ventrally ${ }^{11}$.

Simmen et al. have a neutral approach to both techniques, but they prefer the swing-door method for the inexperienced surgeon ${ }^{8}$.

\section{Uncinectomy In Difficult Situations}

The primary goal of doing uncinectomy is to locate the maxillary sinus ostium. Occasionally this is not possible due to either excessive scarring and polypoid tissue from previous surgery or a very narrow pyriform aperture so that the ostium cannot be localized. Another factor is abnormally lateralized uncinate, where it may be adherent to the lateral wall or hidden behind the lacrimal crest, particularly if there is an active purulent discharge or the field is bloody. In such a situation, one usually has to do some retrograde dissection. Remnants of the bulla ethmoidalis are removed if they are present, and dissection continues from posterior to anterior until the posterior edge of the uncinate process is found. A good trick is to gently palpate the posterior fontanel area with a blunt sucker or ball probe. This is mucosa without underlying bone, and it goes in easily with palpation causing air bubbles to appear from the maxillary ostium. Once the maxillary ostium is found, it is widened posteriorly and inferiorly and joined to any accessory ostium. When necessary, it is widened anteriorly carefully with the backbiter without causing injury to the nasolacrimal duct.

When the previous methods cannot localize the maxillary ostium, some alterative techniques may be helpful.

Posterior Fontanel Approach: The posterior fontanel is part of the medial maxillary wall and located between the tails of the middle and inferior turbinate, behind the hiatus semilunaris and under the bulla ethmoidalis. It is composed of soft tissue covered by mucosa without underlying bone. It is easily identified by gentle palpation of the area with a curved sucker. Once it is identified, an opening is created in its membranous portion using a rightangled ball probe or curved antrum knife. The instrument is slid just above the inferior turbinate in a lateral and inferior direction. The mucosa is punctured as low as possible to avoid injury to the orbit. Also, one has to make sure that the maxillary sinus is not hypoplastic. If an accessory ostium is 
found in the posterior fontanel, it is used instead of creating a new opening. The sucker is pulled forward to enlarge the opening a little, and then a backbiter is inserted in the hole and opened wide so that its jaw lies inside the maxillary sinus. Multiple bites are taken to widen the ostium. The uncinate can be taken up with these bites. It is also essential to join this antrostomy to the natural maxillary ostium to avoid recirculation phenomena. It is vital to remove the uncinate because leaving part of it above the maxillary ostium encourages adhesions and polyps in this narrow space ${ }^{8,10,12}$.

Anterior Fontanel Approach: The anterior fontanel is a membranous part of the medial maxillary wall that lies anterior to the uncinate process. A special curved knife or the curved antrum knife is used to incise the anterior fontanel. It is incised as low as possible, just above the inferior turbinate and anterior to the uncinate process. The maxillary sinus is entered with little resistance, and the caudal part of the uncinate process is severed by moving the knife from anterior to posterior. A suitable scissor is introduced into the hole and used to cut the upper part of the uncinate, which is removed by Blakesley forceps. The procedure may be complex for the less experienced surgeon, and it requires extra care to avoid penetrating the orbit or causing injury to the nasolacrimal system ${ }^{13,14}$.

\section{DISCUSSION}

The distance between the uncinate and lamina papyracea can be as narrow as $0.1 \mathrm{~mm}$ and varies between the two sides. An air cell lateral to the uncinate is found in some people; it increases the distance considerably. The base of the uncinate is directly attached anteriorly to the lacrimal bone and the nasolacrimal duct ${ }^{15}$. Uncinectomy and middle meatal antrostomy are probably the commonest procedures performed during endoscopic sinus surgery. They are related to each other, so when one of them is done, the other is required. They are described as "basic and simple procedures". However, failure of proper uncinectomy and middle meatal antrostomy is one of the commonest causes of revision surgery ${ }^{3,10,11,16}$.

The most significant advantage of the swingdoor technique is the safe and accurate identification of the maxillary ostium. In the classic method, the uncinate is incised anteriorly. If this incision is made too close to the uncinate attachment, the orbital wall may be entered. To avoid such a situation, surgeons tend to leave a few millimetres at the uncinate attachment and make their incision slightly posterior. While this maneuver decreases the incidence of orbital penetration, it makes the identification of maxillary ostium more challenging as it is covered with a remnant of the uncinate process. The swing-door technique has been introduced to overcome this situation. The uncinate is taken in backward fashion incrementally up to its attachment without imposing risk on the orbit. With the classic method, Wormald was unable to identify the maxillary ostium in 42 cases $(6.6 \%)$, while in the swing-door technique, the maxillary ostium was identified in all cases $^{3,4,9}$ as shown in table1.

The two areas at risk during uncinectomy are the nasolacrimal duct and orbit. Other complications as hemorrhage, CSF leak, synechiae, and crustation are not related to the specific technique used for uncinectomy. Literature search showed that the average incidence of orbital penetration in the classic technique is generally low; about $1.5-2 \%$ 17-19. Stammberger reported $1.8 \%$, while Wormald reported $0.94 \%$. However, its incidence was zero in the swing-door technique (table1). The classic technique of uncinectomy has a higher risk of orbital penetration, resulting in exposure of orbital periosteum or orbital fat prolapse, according to the depth and direction of injury. Digital palpation of the globe during surgery will detect orbital injury by causing movement of orbital periosteum. Prolapsed fat should not be teased nor repositioned inside the orbit; rather, it should be left alone. If an accidental orbital injury has occurred, care is required during the rest of the surgery to avoid more damage in this region. The powered instruments should be avoided at this site. If orbital contents are not violated, most of these injuries will heal without a sequel.

Nasolacrimal duct is liable to injury by the backbiter, so it is more likely in the swing-door technique. The backbiter should not be closed if any more than simple resistance is felt. Removal of overlying bone without injury to the duct itself will not cause epiphora, and in many cases, nasolacrimal duct injury will pass unnoticed by the patient and sometimes even by the doctor. If the duct itself is cut or crushed, it should be opened and kept open by a piece of gelfoam. The reported incidence of injury to the lacrimal duct in the classic method is generally less than $1 \%{ }^{18,19}$. Wormald reported an incidence of $0 \%$ and $0.94 \%$ in the classic and swing-door methods respectively ${ }^{3,9}$.

Comparing the two techniques in the hands of the same author shows that the swing-door technique is associated with injury to the lacrimal duct in $(0.94 \%)$ with $p$-value $=0.000$. Failure to identify Maxillary ostium and orbital penetration are more common in the classic method with $p$-value $=$ 0.031 for each of them, as shown in table (2). 


\section{CONCLUSION}

Uncinectomy is a safe procedure in experienced hands whatever technique is used. It is usually the first step in endoscopic sinus surgery and the first surgical maneuver the new rhinologist has to learn. Good understanding of the anatomy and the ability to read the CT scan of the paranasal sinuses in three dimensions are of paramount importance to perform safe and effective surgery. Also, the surgeon should be aware of the possible variations in the anatomy of the paranasal sinuses. For the less experienced surgeon, uncinectomy by the backbiter is safer and carries less risk of inadvertent injury to the orbit. It is worth learning both techniques for the more experienced surgeon as some situations may demand one of them or the other.

\section{RECOMMENDATION}

All methods need to be learned on the cadaveric specimen before the surgeons start doing live surgery, as it is the first step in endoscopic sinus surgery.

Table 1: Comparison of the classic and the swingdoor methods

\begin{tabular}{|l|l|l|l|}
\hline & $\begin{array}{l}\text { Stammbe } \\
\text { rger } \\
\text { Classic } \\
\text { method } \\
\mathrm{n} .=500\end{array}$ & $\begin{array}{l}\text { Wormald } \\
\text { Classic } \\
\text { method } \\
\mathrm{n} .=636\end{array}$ & $\begin{array}{l}\text { Wormald } \\
\text { Swing- } \\
\text { Door } \\
\mathrm{n} .=636\end{array}$ \\
\hline $\begin{array}{l}\text { Maxillary } \\
\text { ostium not } \\
\text { identified }\end{array}$ & 0 & 42 & 0 \\
\hline $\begin{array}{l}\text { Orbital } \\
\text { penetration }\end{array}$ & $9(1.8 \%)$ & $6(0.94 \%)$ & 0 \\
\hline $\begin{array}{l}\text { Nasolacrima } \\
\text { I duct injury }\end{array}$ & 0 & 0 & $6(0.94 \%)$ \\
\hline
\end{tabular}

Table (2): Comparison of the classic and the swing-door methods.

\begin{tabular}{|l|l|l|l|}
\hline \multicolumn{1}{|c|}{$\begin{array}{l}\text { Operation } \\
\text { type }\end{array}$} & $\begin{array}{l}\text { Wormald } \\
\text { Classic } \\
\text { method } \\
\mathrm{n}=636\end{array}$ & $\begin{array}{l}\text { Wormald } \\
\text { Swing- } \\
\text { Door } \\
\mathrm{n}=636\end{array}$ & p-value \\
\hline $\begin{array}{l}\text { Complications } \\
\text { not } \\
\text { identified }\end{array}$ & $\begin{array}{l}42 \\
(6.6 \%)\end{array}$ & $0(0.0 \%)$ & $0.000^{*}$ \\
\hline $\begin{array}{l}\text { Orbital } \\
\text { penetration }\end{array}$ & $\begin{array}{l}6 \\
(0.94 \%)\end{array}$ & $0(0.0 \%)$ & $0.031^{* *}$ \\
\hline $\begin{array}{l}\text { Nasolacrimal duct } \\
\text { injury }\end{array}$ & $0(0.0 \%)$ & $6(0.94 \%)$ & $0.031^{* *}$ \\
\hline
\end{tabular}

${ }^{\star} x 2$ used; **Fissure exact test used

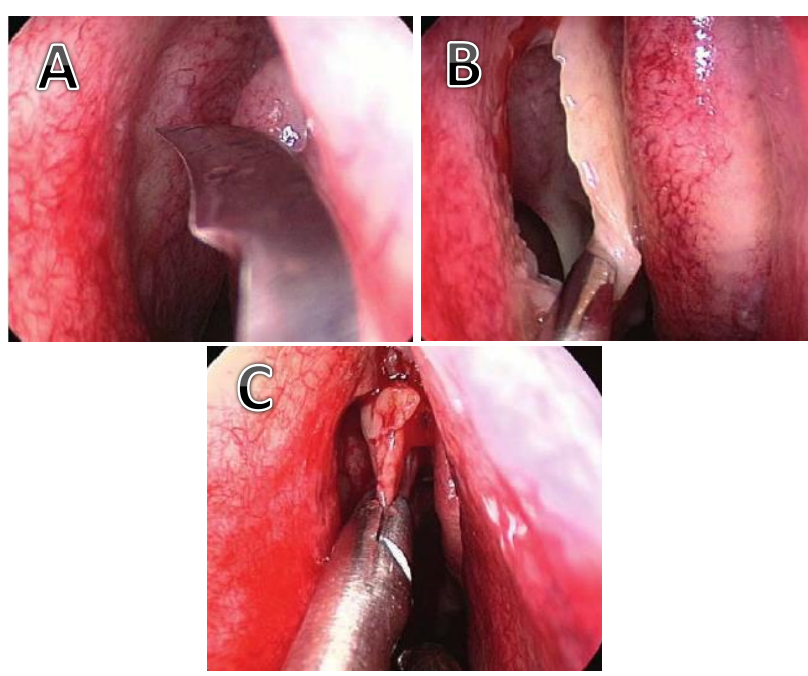

Figure 1. (A) A sickle knife is used to incise the uncinate process close to its attachment. (B) The incision is taken down while the knife is kept in the sagittal plane. At the same time, the knife is used to medialize the uncinate. (C) The uncinate is removed with Blakesley forceps.

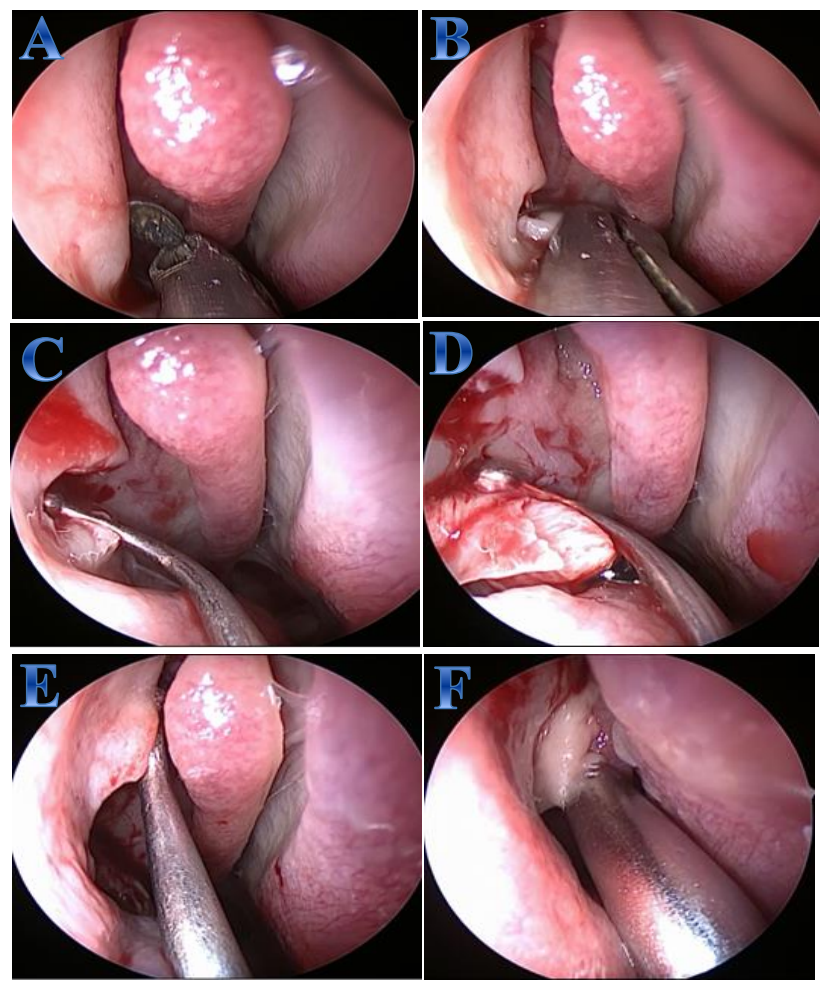

Figure 2. (A) The backbiter's jaw engages the posterior free edge of the uncinate. (B) A horizontal cut is made at the lower portion of the uncinate. Several bites may be taken. (C, D) Ball probe is used to find the maxillary ostium. It also dissects the horizontal part of the uncinate. (E) A curved curette is used to fracture the uncinate ventrally. (F) The uncinate is removed with the microdebrider. 


\section{REFERENCES}

1.Stammberger H. Endoscopic Endonasal Surgery-Concepts in Treatment of Recurring Rhinosinusitis. Part I. Anatomic and Pathophysiologic Considerations. Otolaryngol Neck Surg [Internet]. 1986 Feb;94(2):143-7. Available from: http://journals.sagepub.com/doi/10.1177/019459 988609400202

2. Lund VJ, Stammberger $\mathrm{H}$, Fokkens WJ, Beale T, Bernal-Sprekelsen M, Eloy $P$, et al. European position paper on the anatomical terminology of the internal nose and paranasal sinuses. Rhinology. Supplement. 2014.

3.Brown SM, Fried MP. Book Review: Endoscopic Sinus Surgery: Anatomy, Three-Dimensional Reconstruction, and Surgical Technique. Ann Otol Rhinol Laryngol [Internet]. 2006 Feb;115(2):165-6. Available from: http://journals.sagepub.com/doi/10.1177/000348 940611500217

4.Stammberger H. Endoscopic Endonasal Surgery-Concepts in Treatment of Recurring Rhinosinusitis. Part II. Surgical Technique. Otolaryngol Neck Surg [Internet]. 1986 Feb;94(2):147-56. Available from: http://journals.sagepub.com/doi/10.1177/019459 988609400203

5.Casiano RR. Endoscopic sinus surgery dissection manual: A stepwise: Anatomically based approach to endoscopic sinus surgery. CRC Press; 2002.

6. Stammberger H, Lund V. Scott-Brown's Otorhinolaryngology: Head and Neck Surgery 7Ed [Internet]. 7th ed. Gleeson M, Clarke R, editors. Scott-Brown's Otorhinolaryngology: Head and Neck Surgery 7Ed. London: CRC Press; 2008. 1315-1343 p. Available from: https://www.taylorfrancis.com/books/978144410 9832

7. Fokkens WJ, Lund VJ, Hopkins C, Hellings PW, Kern R, Reitsma S, et al. European Position Paper on Rhinosinusitis and Nasal Polyps 2020. Rhinol J [Internet]. 2020 Feb 1;1-464. Available from:

https://www.rhinologyjournal.com/Documents/Su pplements/supplement_29.pdf

8.Simmen D, Jones N. Manual of Endoscopic Sinus and Skull Base Surgery. Ann R Coll Surg Engl [Internet]. 2014 Apr;96(3):252-252. Available from: https://publishing.rcseng.ac.uk/doi/10.1308/rcsan n.2014.96.3.252a

9.Wormald PJ, McDonogh M. The 'swing-door' technique for uncinectomy in endoscopic sinus surgery. J Laryngol Otol [Internet]. 1998 Jun 29;112(6):547-51. Available from: https://www.cambridge.org/core/product/identifier /S0022215100141052/type/journal_article

10. Kennedy DW, Senior BA. Endoscopic sinus surgery. A review. Otolaryngol Clin North Am. 1997;30(3):313-330.

11. Castelnuovo P. Endoscopic Cadaver Dissection of the Nose and Paranasal Sinuses: An Anatomical-operative Tutorial on the Basic Techniques of Endoscopic Nasal and Paranasal Sinus Surgery. Endo-Press; 2005.

12. Kim HJ, Ahn J-C, Hong S-N, Lee WH, Kim JW. Posterior fontanelle approach for uncinectomy and middle meatal antrostomy in endoscopic sinus surgery. Laryngoscope [Internet]. 2016 Jun;126(6):1311-4. Available from: http://doi.wiley.com/10.1002/lary.25769

13. Lin X, Lin C, Zhang $R$, Wu X. Uncinectomy Through the Anterior Nasal Fontanelle in Endoscopic Sinus Surgery. J Craniofac Surg [Internet]. 2011 Nov;22(6):2220-3. Available from: http://journals.lww.com/00001665201111000-00053

14. Cohen NA, Kennedy DW. Revision Endoscopic Sinus Surgery. Otolaryngol Clin North Am [Internet]. 2006 Jun;39(3):417-35. Available from: https://linkinghub.elsevier.com/retrieve/pii/S0030 666506000168

15. Awad Z, Bhattacharyya M, Jayaraj SM. Anatomical margins of uncinectomy in endoscopic sinus surgery. Int J Surg [Internet]. 2013 Mar;11(2):188-90. Available from: https://linkinghub.elsevier.com/retrieve/pii/S1743 919113000113

16. Alnori H. Endoscopic Sinus Surgery: Indications and Complications. Tikrit Med J. 2013;19(1):89-94.

17. Stankiewicz JA. Complications of endoscopic intranasal ethmoidectomy. Laryngoscope [Internet]. 1987 Nov;97(11):1270-3. Available from: http://doi.wiley.com/10.1288/00005537198711000-00004

18. Levine HL. Functional Endoscopic Sinus Surgery. Laryngoscope [Internet]. 1990 Jan;100(1):79-84. Available from: http://doi.wiley.com/10.1288/00005537199001000-00016

19. Kinsella JB, Calhoun $\mathrm{KH}$, Bradfield JJ, Hokanson JA, Bailey BJ. Complications of endoscopic sinus surgery in a residency training program. Laryngoscope [Internet]. 1995 Oct;105(10):1029-32. Available from: http://doi.wiley.com/10.1288/00005537199510000-00003 